\title{
Research on Age Discrimination against Job Seekers Based on Recruitment Advertisements
}

\author{
Kai Wu${ }^{1,2}$, Chulv Sun ${ }^{3}$ \\ ${ }^{1}$ School of Economic and Management, Tianjin University of Science and Technology, Tianjin, China \\ ${ }^{2}$ College of Management and Economics, Tianjin University, Tianjin, China \\ ${ }^{3}$ Boustead College, Tianjin University of Commerce, Tianjin, China \\ Email: laokaino1@163.com
}

How to cite this paper: $\mathrm{Wu}, \mathrm{K}$. and Sun, C.L. (2021) Research on Age Discrimination against Job Seekers Based on Recruitment Advertisements. Open Access Library Journal, 8: e7961.

https://doi.org/10.4236/oalib.1107961

Received: September 13, 2021

Accepted: October 18, 2021

Published: October 21, 2021

Copyright (c) 2021 by author(s) and Open Access Library Inc.

This work is licensed under the Creative

Commons Attribution International

License (CC BY 4.0).

http://creativecommons.org/licenses/by/4.0/

\section{(c) (i) Open Access}

\begin{abstract}
Under the background of population aging, with the increase of age, the employment rate of workers gradually decreases. Age discrimination against middle-aged and elderly people in enterprises is an important factor. Based on the age requirement in recruitment advertisements, this paper proposes a calculation model for the average age interval to verify the age discrimination in China's labor market. The result shows that the complexity of jobs only affects the lower age limit, and the difference between the upper age limit is very little and tends to convergence, which shortens the effective job-hunting period of high-end talents. The research methods and conclusions have certain theoretical significance for Social Sciences \& Humanities, especially for age discrimination theory. Based on the conclusion, it puts forward some suggestions to alleviate age discrimination.
\end{abstract}

\section{Subject Areas \\ Social Sciences \& Humanities}

\section{Keywords}

Discrimination, Age Limit, Recruitment, the Average Age Interval

\section{Introduction}

With the Economics of Discrimination by Gary S Becker as the main representative in 1957, people have done some research on age discrimination in the labor market. Age discrimination is so widespread, that two-thirds of employees aged 45 - 74 have experienced it. Ageism has become a research focus especially under the background of global aging [1]. However, there are relatively few studies on 
the extent of age discrimination, especially which age group is vulnerable to discrimination, and whether the discrimination in different types of jobs is similar? This paper presents a method of calculating the average age interval from enterprise recruitments. By collecting recruitment advertisements, it verifies the age discrimination in China's labor market and its impact on workers' job hunting.

\section{Literature Review}

People are treated unfairly at work because of age. Is age related to work performance? If age affects work, the age requirements in recruitments are normal responses of enterprises to pursue benefits and should not be regarded as discrimination. Therefore, it needs to be clear whether differential treatment in the recruitment process due to age can be defined as discrimination.

\subsection{Ascertainment of Age Discrimination}

It is undeniable that there are some inherent views on the elderly. Some stereotypes about the elderly believe that with the increase of age, individual work performance continues to decline, and labor skills, especially speed, strength and coordination, continue to decline. For this subjective judgment, scholars have done a lot of empirical research on the relationship between age and performance, and some conclusions are contrary to this view. In terms of comparison between old and young people, Posthuma and Campion found that there is little evidence that work performance declines as workers get older. Performance often improves with age, and when the decline is found, they tend to be small [2].

The physical quality of the middle-aged and the elderly may decline, but it can be made up from experience. $\mathrm{Ng}$ and Feldman provided an expanded metaanalysis on the relationship between age and work performance, and the result showed that age was largely unrelated to task performance in training programs. At the same time, the elderly's performance may actually be slightly superior to younger workers on certain dimensions such as organizational citizenship, safety, and counterproductive work behavior [3].

It is generally believed that the elderly have poor cognitive ability. Avolio and Waldman found differences in the relationship between age and cognitive ability across occupational types but not for different levels of job complexity [4]. People maintain important competencies despite age-related losses, and the relationship between selection and self-reported ability/performance maintenance increased with age [5]. Such a result can be explained by selection, optimization, and compensation (SOC) theory, in which the elderly may compensate for ages [6] [7]. Compared with young people, middle-aged and old people have more advantages in some aspects. Seniors are no more risk averse than juniors and are typically more cooperative; both juniors and seniors respond strongly to competition [8]. Based on the above, the existing research results confirm that there is no direct correlation between age and work performance, and the age limit in recruitment advertisements should be regarded as age discrimination. 
The above pieces of literature show that the work performance of the elderly is not worse than that of young people, but there is still discrimination against the elderly in the workplace. Compared with gender and racial discrimination, age discrimination is more common, about $10 \%$ higher than gender discrimination and twice as much as racial discrimination [9]. The early midlife group (aged 50 - 59) reported more experiences of unfair treatment than the older group but were less likely to attribute their experiences to age discrimination. Finkelstein and Burke simulated employment contexts to verify age discrimination, and found that people subjectively make poor comments on senior employees [10]. Age discrimination is not an individual phenomenon. With the increase of age, the changes of the middle-aged and the elderly in job hunting are getting slim [11]. Perceived workplace age discrimination tends to increase with age [12].

As stereotype and prejudice, age discrimination leads to misunderstandings and worsened work performance [13]. The age discrimination in labor market can take on different forms: hard and soft discrimination. The hard discrimination is the legally prohibited behavior and the soft discrimination is not inscribed in the legal system [14]. Serious age discrimination will even turn into legal cases, and age discrimination litigations occur frequently. Upon litigation cases related to age discrimination from 1993 to 2010, Schrader and Nazarov found that discrimination cases showed an increasing trend [15]. From these results, the middle-aged and the elderly are in disadvantageous positions in the labor market. With the increase of age, the extent of discrimination becomes serious.

\subsection{Theoretical Explanation of Age Discrimination}

In the labor market, people have been treated differently because of race, religion, sex, color, social class, personality, or other non-pecuniary considerations. In 1922, Francis Y Edgeworth, a British economist, first studied gender discrimination [16]. With the economist Gary S Becker's as the main representative, scholars have studied the problem of discrimination in economic activities comprehensively and systematically. According to the Labor Economics, differential treatment due to age can be explained by two major theories: statistical discrimination and taste-based discrimination.

Gary S Becker is inclined to the taste-based discrimination theory, that is, recruiters have a negative impression of the middle-aged and elderly. Even if the middle-aged, the elderly, and young people have the same business performance, they tend to hire young people. However, Lahey believed that statistical discrimination was more obvious than taste-based discrimination [17]. Statistical discrimination is that recruiters can't fully differentiate the professional ability of each candidate, but can only judge individual ability through group characteristics. If statistics show that the business performance of the middle-aged and the elderly is lower than that of young people, they tend to give priority to young 
people. Two kinds of discrimination theories are not opposite to each other. No matter what kind of discrimination, it can be attributed to stereotypes against the middle-aged and the elderly. Some scholars seek other theoretical explanations, such as Triana and Trzebiatowski, who use relative exploitation theory to explain the negative effects caused by age discrimination. They found that perceived over qualification is not only a trigger for relative deprivation, but also a factor that seems to lower an employee's threshold for tolerating discriminatory treatment [18].

\section{Data Description Based on Recruitment Advertisements}

To analyze age discrimination in recruitments, we can select the age data of employees actually employed by the enterprises, but the age requirements in the recruitment advertisements are more suitable. When an enterprise hires employees, it not only considers age, but also integrates many factors such as educational background, major, experience and personality. The age of employees actually employed has been combined by these factors. On the contrary, when designing recruitment advertisements, although enterprises will also consider various factors, the recruitment information is listed in the ideal state, and each factor is relatively independent. Taking recruitment advertisements as the research object is more suitable for analyzing age discrimination.

\subsection{Source of Data and Selection Criteria}

The data are mainly from online recruitment advertisements, including well-known recruitment website such as https://www.51job.com/, http://www.58.com and https://www.zhaopin.com/, et al. In addition, it also includes a small amount of on-site recruitment in Tianjin, Shenzhen, Suzhou, Beijing and other cities. The recruitment information is mainly from large and medium-sized cities across the country. Through omni-directional data selection, it strives to reflect age discrimination in recruitments comprehensively and objectively. To prevent repetition, the data is stored in the ACCESS database with "job + enterprise" as the primary key.

We select four types of jobs, which are handyman, technician, engineer and manager. The work difficulty depends on the technology, knowledge and experience required by enterprise, and the difficulty of four types of jobs increases gradually. Handyman, that is, ordinary worker, also known as manual worker and operator, has fewer requirements for technology and experience, and can take up a job after simple training. Technician, who needs to master a certain skill, must be specially trained or engaged in relevant work. Engineer needs to have systematic learning in professional fields, master professional technology and theoretical knowledge, and have certain working experience. In addition to mastering professional knowledge and administrative skills, manager should also have strong managerial experience. The age requirements in recruitment advertisements generally appear in the form of intervals, including two data points: the lower age limit and the upper age limit. For example, if the age requirement is 22 - 35 years old, the lower age limit is 22 and the upper age limit is 35 . 


\subsection{Basic Description of Age Requirements}

All recruitment data are divided into two samples: the lower age limit and the upper age limit, and each sample are grouped according to the type of job. The statistics index such as quartile, mode, mean and standard deviation can reflect the age requirements of most enterprises. After sorting the age values, the lower quartile is the value in the quarter position, and the upper quartile is the value in the third quarter position. From Table 1, different types of jobs have different requirements for the lower age limit. These statistical indicators such as upper quartile, lower quartile, mode and mean, increase from handyman to manager. The difference of mean between manager and handyman is more than 9 years. It can be preliminarily judged that with the increase of job complexity, the requirements for the lower age limit gradually increase. However, the upper age limit shows a trend of convergence. The difference of mean among four types of job is only 2.16 years. Except that the mode of engineer is 35, the mode of the other three types of job is 45 .

\section{The Average Age Interval of Enterprises Recruitment}

According to the above analysis, there are differences in the age requirements in recruitment, which can be further detailed by the average age interval. The average age interval of a job can be generally accepted by most enterprises. Table 2 shows the meaning of symbols.

Table 1. The basic statistical indicators of age requirements.

\begin{tabular}{cccccccccc}
\hline \multicolumn{2}{c}{ Type of job } & Sample size & The upper quartile & The lower quartile & Mode & Mean & Standard deviation & Skewness & Kurtosis \\
\hline \multirow{6}{*}{$\begin{array}{c}\text { The lower } \\
\text { age limit }\end{array}$} & Handyman & 1159 & 18 & 20 & 18 & 19.37 & 3.244 & 2.485 & 8.793 \\
& Engineer & 1066 & 23 & 25 & 20 & 22.24 & 4.288 & 1.145 & 1.666 \\
& Manager & 1010 & 25 & 28 & 25 & 25.92 & 4.399 & 1.195 & 3.411 \\
\hline \multirow{6}{*}{$\begin{array}{c}\text { The upper } \\
\text { age limit }\end{array}$} & Hechnician & 1263 & 30 & 30 & 28.74 & 4.408 & 0.255 & -0.059 \\
\hline & Engineer & 1066 & 35 & 45 & 45 & 39.29 & 7.067 & -0.009 & -0.325 \\
& Manager & 1010 & 35 & 45 & 45 & 41.22 & 6.402 & -0.167 & -0.034 \\
\hline
\end{tabular}

Table 2. Formula symbol of the lower age limit and its meaning.

\begin{tabular}{cl}
\hline Symbol & \multicolumn{1}{c}{ Meaning } \\
\hline$X_{i, a v g}$ & Average age interval of $i, i \in$ hhandyman, technician, engineer, manager $\}$ \\
$\mu_{i, \text { min }}$ & Population mean of the lower age limit in $i$ \\
$\bar{X}_{i, \text { min }}$ & Sample mean of the lower age limit in $i$ \\
$\sigma_{i, \text { min }}$ & Population standard deviation of the lower age limit in $i$ \\
$S_{i, \text { min }}$ & Sample standard deviation of the lower age limit in $i$ \\
$n_{i}$ & Sample size of $i$ \\
\hline
\end{tabular}

Note: replacing min with max in formula subscript indicates the symbols of the upper age limit. 


\subsection{Analysis Frame}

The average age interval of a certain job is within the population mean of the lower and upper age limit set by most enterprises during recruitment:

$\mu_{i, \text { min }} \leq X_{i, \text { avg }} \leq \mu_{i, \text { max }}$. It is difficult to obtain the population mean of the upper and lower age limit about a certain job in the labor market. However, the population mean can be estimated by sample data. According to the Central Limit Theorem, when the sample size is large enough, the distribution of the sample mean $\bar{X}$ approximately obeys the normal distribution. Therefore, the population mean of the lower and upper age limit in confidence $1-\alpha$ is shown in formula (1):

$$
\left\{\begin{array}{l}
\bar{X}_{i, \min }-\frac{\sigma_{i, \min }}{\sqrt{n_{i}}} z_{\alpha / 2} \leq \mu_{i, \min } \leq \bar{X}_{i, \min }+\frac{\sigma_{i, \text { min }}}{\sqrt{n_{i}}} z_{\alpha / 2} \\
\bar{X}_{i, \max }-\frac{\sigma_{i, \text { max }}}{\sqrt{n_{i}}} z_{\alpha / 2} \leq \mu_{i, \text { max }} \leq \bar{X}_{i, \text { max }}+\frac{\sigma_{i, \text { max }}}{\sqrt{n_{i}}} z_{\alpha / 2}
\end{array}\right.
$$

The population standard deviation $\sigma$ in formula (1) is unknown. Because the sample size is large enough, $\sigma$ is replaced by the sample standard deviation $S$. At this time, the confidence interval of $\mu_{i, \min }$ and $\mu_{i, \max }$ with confidence of $1-\alpha$ is shown in formula (2). It can be concluded that $X_{i, a v g}$ is between the lower limit of $\mu_{i, \min }$ and the upper limit of $\mu_{i, \max }$, as shown in formula (3).

$$
\begin{aligned}
& \left\{\begin{array}{l}
\bar{X}_{i, \text { min }}-\frac{S_{i, \text { min }}}{\sqrt{n_{i}}} z_{\alpha / 2} \leq \mu_{i, \text { min }} \leq \bar{X}_{i, \text { min }}+\frac{S_{i, \text { min }}}{\sqrt{n_{i}}} z_{\alpha / 2} \\
\bar{X}_{i, \text { max }}-\frac{S_{i, \max }}{\sqrt{n_{i}}} z_{\alpha / 2} \leq \mu_{i, \text { max }} \leq \bar{X}_{i, \text { max }}+\frac{S_{i, \max }}{\sqrt{n_{i}}} z_{\alpha / 2}
\end{array}\right. \\
& \bar{X}_{i, \text { min }}-\frac{S_{i, \min }}{\sqrt{n_{i}}} z_{\alpha / 2} \leq X_{i, \text { avg }} \leq \bar{X}_{i, \max }+\frac{S_{i, \max }}{\sqrt{n_{i}}} z_{\alpha / 2}
\end{aligned}
$$

The meaning of formula (3) can be explained by Figure 1. Assuming that the region between point $\mathrm{A}$ and point $\mathrm{B}$ is the interval estimation of $\mu_{i, \min }$, and the region between point $\mathrm{C}$ and point $\mathrm{D}$ is the interval estimation of $\mu_{i, \max }$, formula (3) takes the region between point $\mathrm{A}$ and point $\mathrm{D}$ as the estimated value of the average age interval $X_{i, a v g}$.

\subsection{Analysis Results of the Average Age Interval}

According to the analysis shown in Table 3, when the confidence is $95 \%$, the mean lower age limit of handyman is between 19.18 - 19.55, and the mean upper age limit is between 38.88 - 39.69. It is almost $95 \%$ reliable that the average age interval of handyman is between 19.18 - 39.69. Accordingly, the average age intervals of technician, engineer and manager are $22.00-41.58,25.66-40.88$ and $28.47-41.82$ respectively. Through the average age interval, it is easy to judge age requirement during recruitment.

The more difficult and complex the job is, so the older works usually need to be employed. From handyman, technician, engineer to manager, the job complexity 
Table 3. Analysis results of the average age interval from recruitment advertisements.

\begin{tabular}{|c|c|c|c|c|c|c|c|c|}
\hline & \multicolumn{4}{|c|}{ The lower age limit } & \multicolumn{4}{|c|}{ The upper age limit } \\
\hline & \multirow{2}{*}{$\bar{X}_{i, \min }$} & \multirow{2}{*}{$S_{i, \min }$} & \multicolumn{2}{|c|}{$\begin{array}{c}\text { Estimation interval } \\
\text { under different confidence levels }\end{array}$} & \multirow{2}{*}{$\bar{X}_{i, \max }$} & \multirow{2}{*}{$S_{i, \max }$} & \multicolumn{2}{|c|}{$\begin{array}{l}\text { Estimation interval } \\
\text { under different confidence levels }\end{array}$} \\
\hline & & & $z_{0.99}$ & $z_{0.95}$ & & & $z_{0.95}$ & $z_{0.99}$ \\
\hline Handyman & 19.37 & 3.244 & $19.12-19.61$ & $19.18-19.55$ & 39.29 & 7.067 & $38.88-39.69$ & $38.75-39.82$ \\
\hline Technician & 22.24 & 4.288 & $21.93-22.55$ & $22.00-22.48$ & 41.22 & 6.402 & $40.87-41.58$ & $40.76-41.69$ \\
\hline Engineer & 25.92 & 4.399 & $25.57-26.27$ & $25.66-26.19$ & 40.46 & 6.945 & $40.04-\mathbf{4 0 . 8 8}$ & $39.91-41.01$ \\
\hline Manager & 28.74 & 4.408 & $28.38-29.10$ & $28.47-29.01$ & 41.45 & 6.085 & $41.07-41.82$ & $40.95-41.94$ \\
\hline
\end{tabular}

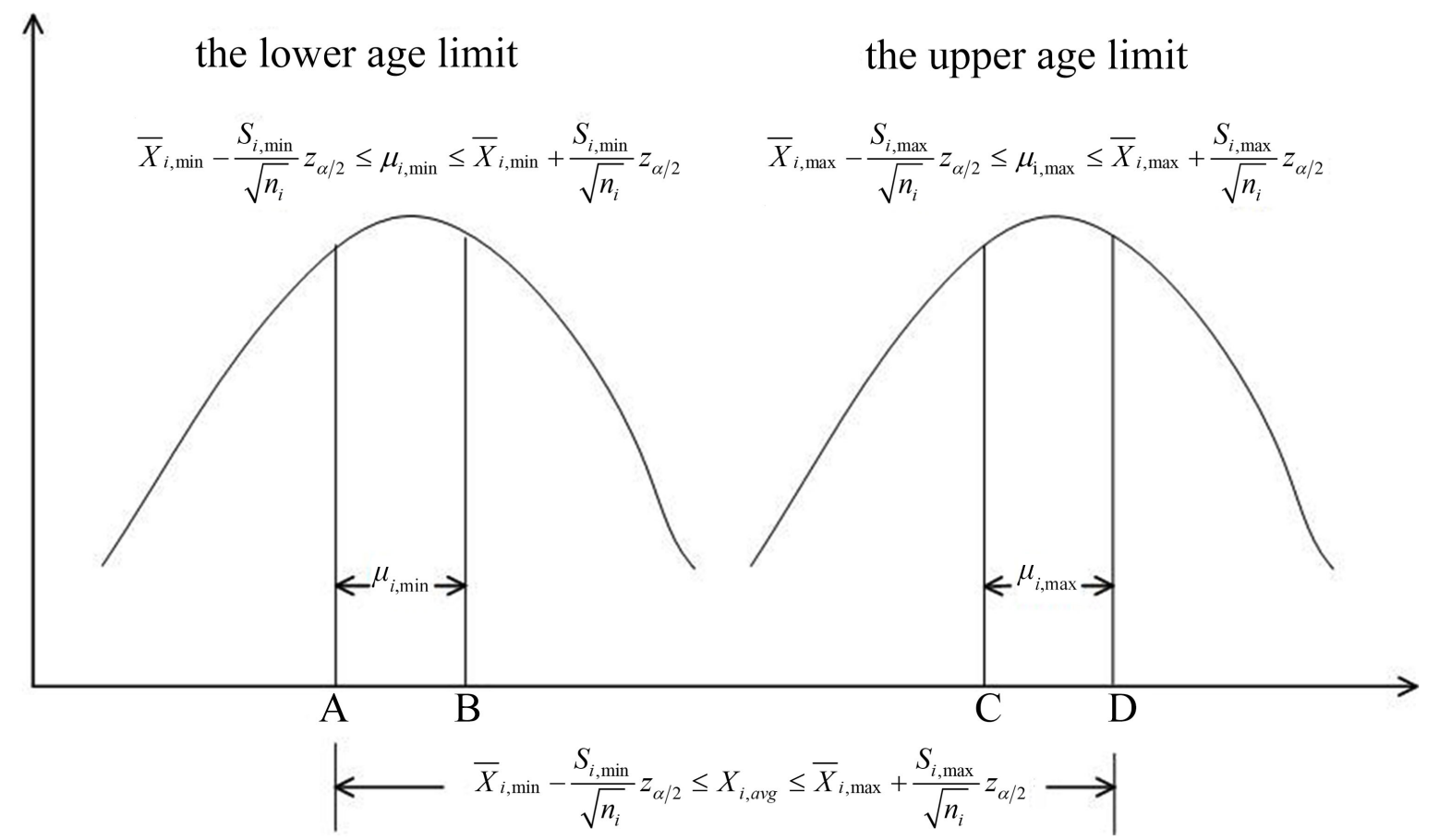

Figure 1. Demonstration of the average age interval.

increases in turn, and the requirements for the lower age limit increase gradually. Such a result can be explained by the derivation of labor demand. Employees, like other production factors, are a kind of induced demand, which depends on the complexity and characteristic of the job. The purpose of recruiting employees is to provide products and services for the market. Therefore, employees must meet the job requirements to complete work tasks. The technology, knowledge and experience of employee gradually accumulate with age. Just as diploma, work experience and professional title, age has become a reference to measure employee. The ability of job seekers can be preliminarily judged by age. Generally, enterprises can recruit 20-year-old employees to engage in relatively simple work, but it is almost impossible to recruit a 20 -year-old manager. The more complex the job, the greater the requirements for the lower age limit, which is the rational choice of enterprises. 
The upper age limit for all kinds of jobs tends to converge, generally around 40 years old. Such a result is not the rational choice of enterprises, and can't be explained by the derivation of labor demand. Enterprises set the upper age limit at 40 years around, so there is age discrimination against the middle-aged and the elderly. Becker explains this phenomenon with taste-based discrimination. Enterprises have a negative impression on the middle-aged and the elderly. Even if the work performance of middle-aged, elderly and young people is similar, they tend to hire young people. These negative impressions include: the middle-aged and the elderly have a low educational background, low learning ability, lack of enterprising spirit, relatively backward skills, physical and mental decline, etc. Whether these negative impressions are correct or not, remains to be discussed. For example, people usually think that the physical and mental capabilities of the elderly are weak; however, Posthuma and Campion [2] showed that the capabilities decreases are very little and could be compensated by work experience. At the same time, it is generally believed that the cognitive function of the elderly declines with age, but the research of Abraham and Hansson [5] showed that there was no significant correlation between cognitive function and work performance, and the decline of cognitive abilities did not hinder work.

Effective job-hunting years decrease with the increase of job requirements. As shown in Table 3, handyman can apply for job from the age of 19; however, manager could be generally accepted until the age of 28 . Moreover, the upper age limit of both types of jobs is about 40 . From handyman to manager, with the increase of job complexity, the requirements for job seekers are more stringent. Engineer and manager should not only have professional diplomas, but also have work experience. To meet these requirements, job seekers need to invest time and energy to accumulate gradually. However, from the perspective of enterprises, there is no extension of the upper age limit for job seekers' early time investment. No matter what kind of jobs, after over 40 years old, job seekers gradually lose the opportunity to apply for new jobs, which is a waste of talent resources caused by age discrimination.

\section{Conclusions}

At present, China's labor supply is relatively sufficient, which provides conditions for age discrimination in enterprises recruitment. The age requirements in recruitment advertisements are independently designed by enterprises according to the job characteristics. Through collecting recruitment advertisements and statistical analysis, it can show the regularity of age discrimination. This paper provides a simple and practical method for studying age discrimination: By selecting the age requirements from recruitment advertisements and using the average age interval model, the age preferences of enterprises are calculated. The results confirm that there is age discrimination.

If the technical, knowledge and experience requirements of the job are simple, the requirements for the lower age limit will be reduced accordingly. Such a re- 
sult can be explained by the derivation of labor demand, which is the rational choice of enterprises. However, the upper age limit tends to be convergence, generally around the age of 40 . Such a result is consistent with Becker's the taste-based discrimination theory, which confirms the existence of age discrimination against middle-aged and elderly job seekers. The convergence of the upper age limit leads to the higher job requirements, the shorter the effective job-hunting years of seekers. Complex works require job seekers to invest more time and energy, but from the perspective of enterprises, the upper age limit has not been extended for job seekers' time investment. Such recruitment phenomenon needs to be vigilant. The upper age limit converges to 40 years old around. After that, the labor participation rate and employment rate gradually decrease, resulting in a waste of human resources. It is necessary for the government to guide the employment policy and change the employment concept of enterprises. From the perspective of ensuring people's livelihood, it should protect workers from discrimination.

Referring to others' experiences, some countries have paid attention to age discrimination and legislated to protect the elderly from discrimination. The European Council issued a decree prohibiting age discrimination in employment [19]. South Korea promulgated the Age Discrimination Prohibition Legislation (ADPL) in 2008 to promote the employment of middle-aged and old people [20]. In addition to legislation, some countries have established professional institutions to solve age discrimination disputes. For example, the Equal Employment Opportunity Commission was established in the United States to specifically handle employment discrimination [18]. In the EU, age discrimination cases are judged by the Court of Justice of the European Union (CJEU) [21]. The Australian Human Rights Commission (AHRC) has conducted widely to improve attitudes to aging and combat ageism; especially, it appointed an Age Discrimination Commissioner to address the problem nationally [22]. The practices of these countries are worth learning.

This paper collects recruitment advertisements to study age discrimination, without combining with gender, region and other factors, especially the industry environment, technical characteristics, enterprise scale, cultural customs, etc. These factors will have impacts on the age requirements, which is the direction that needs to be further discussed. At the same time, age discrimination not only occurs in the recruitment process but also in the production and operation of enterprises. For example, the opportunities for promotion and training of the middle-aged and the elderly are relatively small, and they are more likely to be dismissed in advance. Although this paper does not cover these contents, such phenomena should be vigilant.

\section{Acknowledgements}

We would like to acknowledge financial support from Tianjin philosophy and social science planning project (Grants No. TJGL16-021). 


\section{Conflicts of Interest}

The authors declare no conflicts of interest.

\section{References}

[1] Levy, S.R. and Macdonald, J.L. (2016) Progress on Understanding Ageism. Journal of Social Issues, 1, 5-25. https://doi.org/10.1111/josi.12153

[2] Posthuma, R.A. and Campion, M.A. (2009) Age Stereotypes in The Workplace: Common Stereotypes, Moderators, and Future Research Directions. Journal of Management, 35, 158-188. https://doi.org/10.1177/0149206308318617

[3] Ng, T.W.H. and Feldman, D.C. (2008) The Relationship of Age to Ten Dimensions of Job Performance. Journal of Applied Psychology, 93, 392-423. https://doi.org/10.1037/0021-9010.93.2.392

[4] Avolio, B.J. and Waldman, D.A. (1990) An Examination of Age and Cognitive Test Performance Across Job Complexity and Occupational Types. Journal of Applied Psychology, 75, 43-50. https://doi.org/10.1037/0021-9010.75.1.43

[5] Abraham, J.D. and Hansson, R.O. (1995) Successful Aging at Work: An Applied Study of Selection, Optimization, and Compensation through Impression Management. The Journals of Gerontology, 50B, 94-103.

https://doi.org/10.1093/geronb/50B.2.P94

[6] Baltes, P.B. (1997) On the Incomplete Architecture of Human Ontogeny: Selection, Optimization, and Compensation as Foundation of Developmental Theory. American Psychologist, 52, 366-380. https://doi.org/10.1037/0003-066X.52.4.366

[7] Rudolph, C.W. (2016) Lifespan Developmental Perspectives on Working: A Literature Review of Motivational Theories. Work, Aging and Retirement, 2, 130-158. https://doi.org/10.1093/workar/waw012

[8] Charness, G. and Villeval, M.C. (2009) Cooperation and Competition in Intergenerational Experiments in the Field and the Laboratory. American Economic Review, 99, 956-978. https://doi.org/10.1257/aer.99.3.956

[9] Liat, A. (2014) Perceived Age, Gender, and Racial/Ethnic Discrimination in Europe: Results from the European Social Survey. Educational Gerontology, 40, 499-517. https://doi.org/10.1080/03601277.2013.845490

[10] Finkelstein, L.M., Burke, M.J. and Raju, M.S. (1995) Age Discrimination in Simulated Employment Contexts: An Integrative Analysis. Journal of Applied Psychology, 80, 652-663. https://doi.org/10.1037/0021-9010.80.6.652

[11] Drydakis, N., MacDonald, P., Chiotis, V. and Somers, L. (2018) Age Discrimination in the UK Labour Market. Does Race Moderate Ageism? An Experimental Investigation. Applied Economics Letters, 25, 1-4. https://doi.org/10.1080/13504851.2017.1290763

[12] Marchiondo, L.A., Gonzales, E. and Williams, L.J. (2019) Trajectories of Perceived Workplace Age Discrimination and Long-Term Associations with Mental, Self-Rated, and Occupational Health. The Journals of Gerontology. Series B, 74, 655-663. https://doi.org/10.1093/geronb/gbx095

[13] King, S.P. and Bryant, F.B. (2017) The Workplace Intergenerational Climate Scale (WICS): A Self-Report Instrument Measuring Ageism in the Workplace. Journal of Organizational Behavior, 38, 124-151. https://doi.org/10.1002/job.2118

[14] Stypinska, J. and Turek, K. (2017) Hard and Soft Age Discrimination: The Dual Nature of Workplace Discrimination. European Journal of Ageing, 14, 49-61. https://doi.org/10.1007/s10433-016-0407-y 
[15] Schrader, S. and Nazarov, Z.E. (2016) Trends and Patterns in Age Discrimination in Employment Act (ADEA) Charges. Research on Aging, 38, 580-601. https://doi.org/10.1177/0164027515593989

[16] Edgeworth, F.Y. (1922) Equal Pay to Men and Women for Equal Work. The Economic Journal, 32, 431-457. https://doi.org/10.2307/2223426

[17] Lahey, J.N. (2008) Age, Women, and Hiring: An Experimental Study. Journal of Human Resources, 43, 30-56. https://doi.org/10.3368/jhr.43.1.30

[18] Triana, M.C., Trzebiatowski, T. and Byun, S.Y. (2017) Lowering the Threshold for Feeling Mistreated: Perceived Overqualification Moderates the Effects of Perceived Age Discrimination on Job Withdrawal and Somatic Symptoms. Human Resource Management, 56, 979-994. https://doi.org/10.1002/hrm.21812

[19] Dewhurst, E. (2015) Are Older Workers Past Their Sell-By-Date? A View from UK Age Discrimination Law. Modern Law Review, 78, 189-215. https://doi.org/10.1111/1468-2230.12113

[20] Rhee, H.C., Woo, K. and Cho, J. (2014) Identifying the Winners under the Age Discrimination Prohibition Legislation in Korea: Policy Remedy for Redistribution. Journal of the Asia Pacific Economy, 19, 186-201.

https://doi.org/10.1080/13547860.2013.818427

[21] Bengtsson, L. (2020) Addressing Age Stereotyping against Older Workers in Employment: The CJEU and UK Approach. International Journal of Law and Management, 62, 67-92. https://doi.org/10.1108/IJLMA-01-2019-0019

[22] O’loughlin, K., Kendig, H., Hussain, R. and Cannon, L. (2017) Age Discrimination in the Workplace: The More Things Change... Australasian Journal on Ageing, 36, 98-101. https://doi.org/10.1111/ajag.12429 